\title{
Adsorption of phenylalanine onto polymeric resins: equilibrium, kinetics and operation of a parametric pumping unit
}

\author{
Sergi Díez ${ }^{a}$, Anabela Leitão ${ }^{b}$, Licínio Ferreira ${ }^{c}$, Alírio Rodrigues ${ }^{\mathrm{d}, *}$ \\ ${ }^{a}$ Department of Civil and Environmental Engineering, Massachusetts Institute of Technology, \\ Cambridge, MA 02139, USA \\ ${ }^{\mathrm{b}}$ Universidade Agostinho Neto, Departamento de Engenharia Quimica, Luanda, Angola \\ - Universidade de Coimbra, Departamento de Engenharia Química, 3000 Coimbra, Portugal \\ ${ }^{\mathrm{d}}$ Laboratory of Separation and Reaction Engineering, School of Engineering, University of Porto, \\ 4099 Porto Codex, Portugal
}

Accepted 4 September 1997

\begin{abstract}
Adsorption of D, L-Phenylalanine onto polymeric adsorbents (Amberlite XAD-4 and XAD-16; Sephabeads SP206 and SP207) was studied. Adsorption equilibrium isotherms were measured by batch equilibration at 15 and $40^{\circ} \mathrm{C}$, showing the possibility of using a parametric pumping technique for aminoacid purification/recovery. Dynamic studies in a laboratory adsorption column Amicon Column $(22 \times 500 \mathrm{~mm})$ were carried out to further screen adsorbents and obtain mass transfer parameters to be used in the modeling, simulation and operation of the pilot parametric pumping unit. The pilot plant includes a Amicon Columnn $(90 \times 1000 \mathrm{~mm})$ and is completely automated. A package for the simulation of this cyclic operation was developed. Simulated and experimental results using Sephabeads SP206 (Mitsubishi Kasei Corporation, Japan) are in good agreement. (C) 1998 Elsevier Science B.V.
\end{abstract}

Keywords: Adsorption; parametric pumping; phenylalanine; purification

\section{Introduction}

Adsorptive separations are widely used in chemical engineering applications for the purification of fluid streams, recovery of solutes and bulk separations. The importance of adsorption processes has been recently stressed in various reviews [1-3]. Conventional fixed-bed processes involve saturation, adsorption or loading step followed by desorption, elution or regeneration steps and eventually washing steps. The performance of

* Corresponding author. fixed-bed adsorption is governed in the first instance by the nature of the adsorption equilibrium isotherm. The simplest equilibrium model tells us that the breakthrough curve will be a shock (compressive wave) in the case of favorable isotherms (Langmuir type) and a dispersive wave in the case of unfavorable isotherms. For linear isotherms, equilibrium theory predicts a contact discontinuity for a step input on the feed concentration. The overall economy of the process must therefore consider the complete cycle. A favorable isotherm is convenient as far as adsorption is concerned, but regeneration is more difficult. 
Fixed-bed regeneration in conventional processes involves the use of chemicals, $\mathrm{pH}$ changes, temperature changes or pressure changes in the case of gas adsorption processes. Thermal parametric pumping, however, does not use chemical regenerant; desorption is achieved by changing the temperature of the solution (recuperative mode) together with a change in the flow direction. This cyclic process invented by Wilhelm et al. [4] stabilizes a temperature profile inside the bed as in the case of flow reversal reactors. Obviously, parametric pumping can only be considered if adsorption equilibrium isotherms change significantly with temperature. Previous work in our laboratory dealt with aqueous phenolic solutions and polymeric adsorbent Duolite ES861 (Rohm and Haas, France) and was reported elsewhere [5,6].

In this work the adsorption of phenylalanine in polymeric adsorbents will be studied. Work on adsorption of aminoacids on ion exchangers has been carried out previously [7-11]; other supports have also been used for phenylalanine adsorption $[12,13]$. Polymeric adsorbents have been extensively tested for aminoacid adsorption [14-16].

The objective of this work is the study of adsorptive separation of phenylalanine by parametric pumping. The methodology is as follows:

(1) Measurement of adsorption equilibrium isotherms of phenylalanine in various polymeric adsorbents (Amberlite XAD-4, XAD-16, Sephabeads SP206, SP207) at different temperatures $\left(15\right.$ and $40^{\circ} \mathrm{C}$ ) in order to screen resins for further use in parametric pumping.

(2) To study adsorption kinetics in fixed-bed laboratory columns at various temperatures.
(3) To operate a parametric pumping pilot unit for the adsorptive separation of phenylalanine and compare experimental results with simulated results obtained with our proprietary package of parametric pumping cycles.

\section{Experimental}

\subsection{Chemicals and adsorhents}

D, L-Phenylalanine (a neutral amino acid) was obtained from Sigma-Aldrich (Spain), and $\mathrm{KH}_{2} \mathrm{PO}_{4}$ from Carlo Erba (Italy). Various polymeric resins were used in this study: Amberlite XAD-4 and XAD-16 (Rohm and Haas, France) and Sephabeads SP206 and SP207 (Mitsubishi Kasei Corporation) purchased from Resindion (Italy). The physical characteristics of these resins are summarized in Table 1 . All the solutions and buffers used were prepared with distilled water.

\subsection{Equipment and methods}

\subsubsection{Batch adsorption}

Adsorption equilibrium isotherms were measured by batch equilibration using a GLF (model 3018, Germany) shaking mixer. An Edmund Bühler thermostatic bath (model UKT80, Germany) was used for temperature control. A typical run is described as follows: a stock Phe solution was prepared by dissolving solid phenylalanine in $0.01 \mathrm{M}$ phosphate buffer; the ionic strength of the solution was kept at $0.01 \mathrm{M}$ $\left(\mathrm{KH}_{2} \mathrm{PO}_{4} \mathrm{pH}=6.5\right.$, adjusted by $\left.\mathrm{NaOH}\right)$. A known

Table 1

Physical properties of polymeric resins used for phenylalanine adsorption

\begin{tabular}{|c|c|c|c|c|}
\hline Adsorbent & Amberlite XAD4 & Amberlite XAD16 & Sepabeads SP206 & Sepabeads SP207 \\
\hline Matrix & $\begin{array}{l}\text { Macroreticular cross- } \\
\text { linked aromatic }\end{array}$ & Macroreticular & $\begin{array}{l}\text { Aromatic porous resin with } \\
\text { hydrophobic substituents }\end{array}$ & $\begin{array}{l}\text { Aromatic porous resin with } \\
\text { hydrophobic substituents }\end{array}$ \\
\hline Physical form & $\begin{array}{l}\text { White translucent } \\
\text { beads }\end{array}$ & $\begin{array}{l}\text { White translucent } \\
\text { beads }\end{array}$ & Yellow opaque beads & Brown opaque beads \\
\hline Moisture content (\%) & $44-50$ & $62-70$ & 50.0 & 50.4 \\
\hline Specific surface area $\left(\mathrm{m}^{2} \mathrm{~g}^{-1}\right)$ & $\geq 700$ & $\geq 800$ & 556 & 627 \\
\hline $\begin{array}{l}\text { Specific gravity, } \\
\text { (g wet resin } \mathrm{ml} \mathrm{resin}^{-1} \text { ) }\end{array}$ & $1.05-1.09$ & $1.015-1.025$ & 1.19 & 1.18 \\
\hline Particle size (mm) & 0.75 & 0.75 & 0.40 & 0.40 \\
\hline
\end{tabular}


volume $(25 \mathrm{ml})$ of aqueous solution of Phe with concentration in the range $10^{-3}-0.05 \mathrm{M}$ was poured into a volumetric flask containing $3 \mathrm{~g}$ of a polymeric adsorbent. The volumetric flask was then placed in a shaking mixer for $15 \mathrm{~h}$ (the time required to reach equilibrium) using a thermostatic bath. The solution was separated from the resin and the concentration of phenylalanine in solution $\mathrm{C}^{*}$ analyzed by UV spectrophotometry at $275.2 \mathrm{~nm}$ using a Jasco (model 7800, Japan).

\subsubsection{Laboratory-scale fixed-bed adsorption}

Dynamic column experiments were carried out with a Amicon Column $(22 \times 500 \mathrm{~mm})$ (England) equipped with a jacket for temperature control. A peristaltic pump Gilson (model Minipuls 2, France) was used to pass the reactant through the column. Phenylalanine concentration at the column outlet was measured as described above.

\subsubsection{Parametric pump pilot plant}

Parametric pumping experiments were carried out in the completely automated pilot plant shown in Fig. 1, described in detail elsewhere [6].

The experimental set-up for recuperative parametric pumping contains four sections: (1) column and ancillary equipment; (2) product receivers; (3) sampling, collector and analytical devices; and (4) automation section.

The column is a borosilicate column Amicon G90 $\times 1000$, with $0.09 \mathrm{~m}$ internal diameter and $1 \mathrm{~m}$ height. Two thermocouples (type $\mathrm{K}$ ) are installed axially to measure temperature waves. The solution is passed through the column either downward (cold half-cycle, $15^{\circ} \mathrm{C}$ ) or upward (hot half-cycle, $40^{\circ} \mathrm{C}$ ) using peristaltic pumps 15 or 16 , respectively. During downward flow, valve 11 is open and valve 12 closed; at the same time valves position is reserved during upward flow. The liquid solution is heated or cooled by heat exchangers, 6 and 7. Bubble traps are implemented inside the fixed bed to prevent gassing.

The pilot plant has three reservoirs: top, bottom and feed. The top reservoir receives product when solution is passed in upward flow. The bottom reservoir receives product when solution is passed in downward flow. The feed reservoir is used to pass fresh solution to the top reservoir when pump
18 is on. To detect when one half-cycle ends three pressure transducers are installed at the bottom of each reservoir.

Sampling of bottom and top products was carried out using a fraction collector, when pumps 19 and 17 work. Fraction collector 5 is equipped with a controller interface in continuous communication with the computer. Solution is passed to fraction collector or to the drain by using threeway solenoid valves 13 and 14 . Finally, phenylalanine concentration in samples was analyzed by $\mathrm{UV}$ at $275.2 \mathrm{~nm}$.

Operation of pilot plant was performed in a semi-continuous mode, with feed to the top reservoir during the hot half-cycle and product (either top or bottom) withdrawals continuously done.

\section{Results and discussion}

\subsection{Adsorption equilibrium isotherms from batch adsorption experiments}

To design parametric pumping experiments adsorption equilibrium isotherms of Phe in the adsorbent resin at two different temperatures are required. The affinity of Phe for a given adsorbent was evaluated for two temperatures $\left(15\right.$ and $\left.40^{\circ} \mathrm{C}\right)$.

The equilibrium adsorption isotherms of phenylalanine (Phe) onto macroporous adsorbent resins were measured by batch equilibration of a known mass of resin with a given volume of Phe solution of known concentration. When equilibrium is reached the concentration of Phe in solution $C^{*}$ is measured and the adsorbed phase concentration $q^{*}$ is calculated by material balance. The Phe concentration adsorbed in the resin $q^{*}$ was calculated by material balance.

The experimental data $\left(q^{*}, C^{*}\right)$ of adsorption equilibrium isotherms of Phe onto the polymeric adsorbents were fitted by the Langmuir equation:

$q^{*}=\frac{Q_{\mathrm{L}} K_{\mathrm{L}} C^{*}}{1+K_{\mathrm{L}} C^{*}}$,

where $q^{*}$ (mol Phe adsorbed $\mathrm{g}$ wet resin $^{-1}$ ) and $C^{*}$ (mol Phe litter solution ${ }^{-1}$ ) are concentrations 

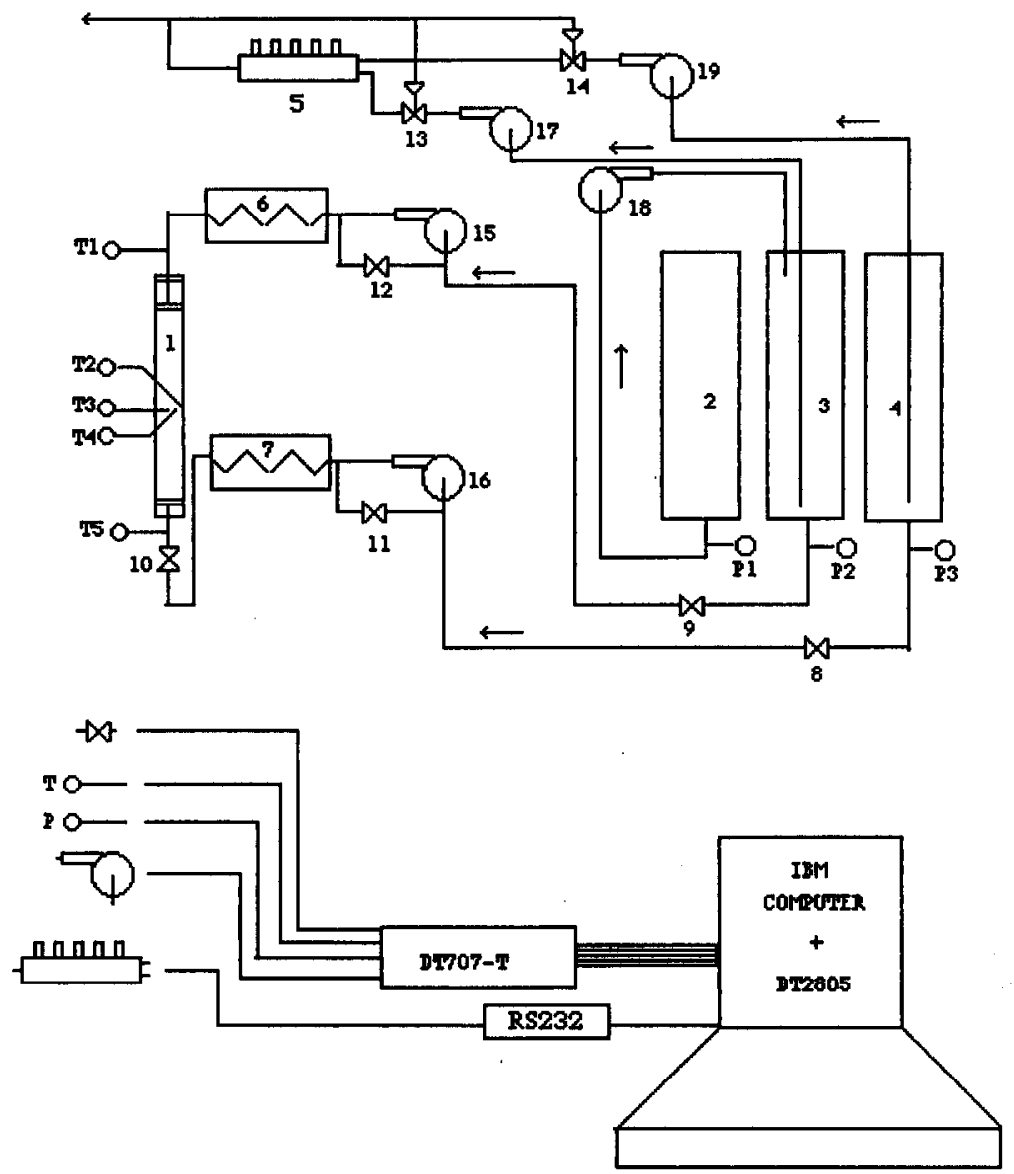

Fig. 1. Experimental set-up of the parametric pumping pilot plant. Legend: (1) glass column G90-Amicon; (2) feed reservoir; (3) top reservoir; (4) bottom reservoir; (5) fraction collector Gilson; (6) and (7) heat exchangers; (8)-(12) two-ways solenoid valves; (13) and (14) three-ways solenoid valves; (15) and (16) peristaltic pumps Watson Marlow; (17)-(19) peristaltic pumps Gilson; (T1)-(T5) thermocouples (type K); (P1)-(P3) pressure transducers Schaevitz (type P510).

in equilibrium of Phe in the adsorbent and liquid phases, respectively.

Experimental results are shown in Figs. 2-5, for Amberlite XAD4, XAD16, SP206 and SP207, respectively. Fitted values of the monolayer capacity $Q_{\mathrm{L}}$ and equilibrium constant $K_{\mathrm{L}}$ for different resins used, at 15 and $40^{\circ} \mathrm{C}$, are shown in Table 2.

In the low concentration range of $\mathrm{Phe}$ in solution to be used in parametric pumping experiments the equilibrium data can be approximately represented by a linear isotherm, Eq. (2), which allows us to make simple predictions of separation performance based on equilibrium model:

$q^{*}=K(T) C^{*}$.
Table 3 shows $K(T)$ values for the systems Phe/polymeric adsorbent. The separation potential measured by the parameter $b$ introduced by Pigford et al. [17] is

$$
b=\frac{a}{1+\bar{m}}
$$

where the average slope $\bar{m}=\left[m\left(T_{1}\right)+m\left(T_{2}\right)\right] / 2$, the deviation $a=\left[m\left(T_{1}\right)-m\left(T_{2}\right)\right] / 2$, evaluted between the cold temperature $T_{1}$ and the hot temperature $T_{2}$, and the capacity parameter $m(T)=\left[(1-\epsilon) \rho_{\mathrm{h}} K(T)\right] / \epsilon$.

As it can seen in Table 3, the adsorbent SP206 presents the larger $b$ parameter value $(b=0.35)$. 


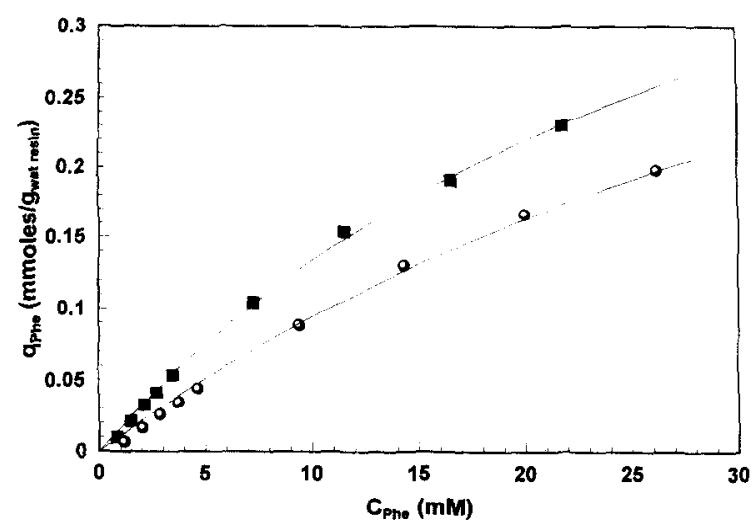

Fig. 2. Adsorption equilibrium isotherms for phenylalanine on XAD4: (D) experimental data at $15^{\circ} \mathrm{C}$; $(O)$ experimental data at $40^{\circ} \mathrm{C}$; (-) fitting with Langmuir equation.

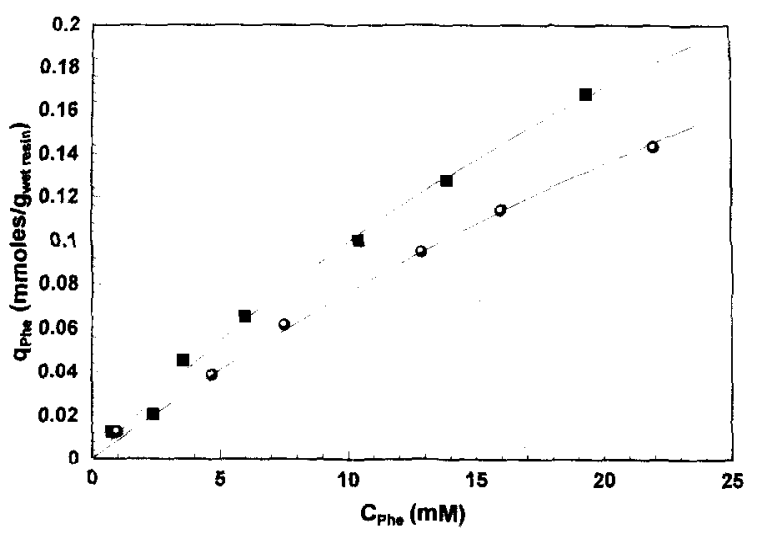

Fig. 3. Adsorption equilibrium isotherms for phenylalanine on XAD16; (Q) experimental data at $15^{\circ} \mathrm{C}$; (O) experimental data at $40^{\circ} \mathrm{C}$; (- - ) fitting with Langmuir equation.

This resin was selected for parametric pumping studies; however, we decided to also carry out mass transfer studies in laboratory fixed-bed columns on Amberlite XAD-4 which has a $b$ value of 0.15 .

\subsection{Kinetics of fixed-bed adsorption at laboratory- scale and pilot-scale}

This section is devoted to dynamic studies of adsorption of phenylalanine by polymeric adsorbents, XAD-4 and SP206, in laboratory and pilot fixed-bed columns. We have analyzed results from the breakthrough and desorption experiments in

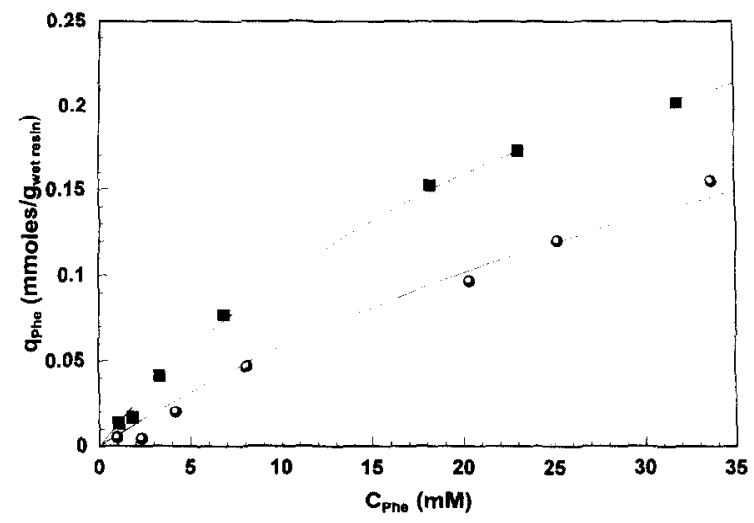

Fig. 4. Adsorption equilibrium isotherms for phenylalanine on SP206; (D) experimental data at $15^{\circ} \mathrm{C}$; $(\mathrm{O})$ experimental data at $40^{\circ} \mathrm{C}$; (

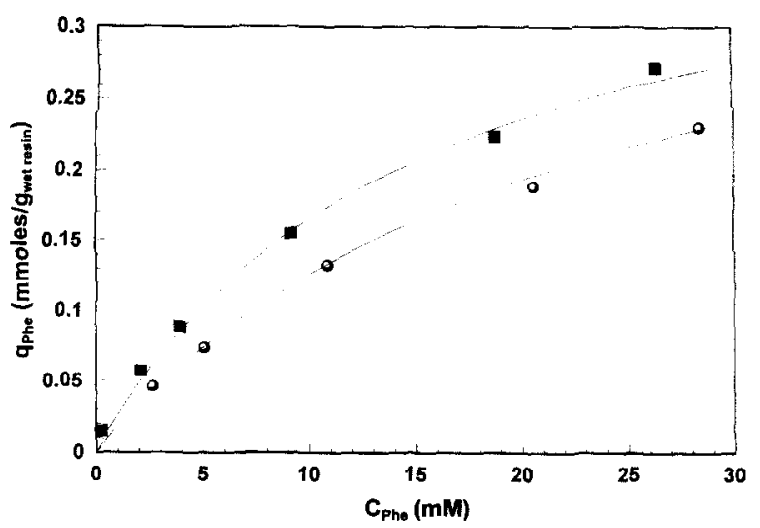

Fig. 5. Adsorption equilibrium isotherms for phenylalanine on SP207; (D) experimental data at $15^{\circ} \mathrm{C}$; (O) experimental data at $40^{\circ} \mathrm{C} ;(-)$ fitting with Langmuir equation.

Table 2

Equilibrium parameters of the Langmuir isotherm for adsorption of Phe in polymeric adsorbents

\begin{tabular}{lllll}
\hline Resin & \multicolumn{2}{c}{$K_{\mathrm{L}}\left(1 \mathrm{~mol}^{-1}\right)$} & \multicolumn{2}{c}{$Q_{\mathrm{L}} \times 10^{5}\left(\mathrm{~mol} \mathrm{~g}^{-1}\right)$} \\
& $15^{\circ} \mathrm{C}$ & $40^{\circ} \mathrm{C}$ & $15^{\circ} \mathrm{C}$ & $40^{\circ} \mathrm{C}$ \\
\hline XAD-4 & 28.08 & 18.28 & 61.00 & 61.00 \\
XAD-16 & 20.33 & 14.95 & 59.09 & 59.09 \\
SP206 & 32.95 & 17.07 & 39.90 & 39.90 \\
SP207 & 66.58 & 43.90 & 41.70 & 40.80 \\
\hline
\end{tabular}

order to evaluate mass transfer parameters. The information obtained from that analysis should be then incorporated in a model that simulates para- 
Table 3

Equilibrium data for the system Phe/polymeric resin in the low concentration range and separation parameter $b$

\begin{tabular}{|c|c|c|c|c|c|c|c|}
\hline \multirow[t]{2}{*}{ System } & \multicolumn{2}{|c|}{$K \times 10^{2}\left(1\right.$ solute g wet resin $\left.{ }^{-1}\right)$} & \multicolumn{2}{|l|}{$m$} & \multirow[t]{2}{*}{$a$} & \multirow[t]{2}{*}{$\bar{m}$} & \multirow[t]{2}{*}{$b$} \\
\hline & $15^{\circ} \mathrm{C}$ & $40^{\circ} \mathrm{C}$ & $15^{\circ} \mathrm{C}$ & $40^{\circ} \mathrm{C}$ & & & \\
\hline Phe/XAD-4 & 1.363 & 0.993 & 22.29 & 16.24 & 3.03 & 19.27 & 0.15 \\
\hline Phe/XAD-16 & 1.091 & 0.730 & 16.77 & 11.22 & 2.78 & 14.00 & 0.19 \\
\hline Phe/SP-206 & 1.214 & 0.563 & 21.67 & 10.05 & 5.81 & 15.86 & 0.35 \\
\hline Phe/SP-207 & 1.629 & 1.193 & 28.83 & 21.12 & 3.86 & 25 & 0.15 \\
\hline
\end{tabular}

Table 4

Experimental conditions for the fixed bed experiments

\begin{tabular}{|c|c|c|c|c|c|c|c|c|}
\hline \multicolumn{9}{|c|}{ Laboratory-scale experiments } \\
\hline Run & Resin type & $C_{\mathrm{E}}(\mathrm{mM})$ & $L(\mathrm{~m})$ & $d(\mathrm{~m})$ & $Q \times 10^{6}\left(\mathrm{~m}^{3} \mathrm{~s}^{-1}\right)$ & $\tau(\min )$ & $\xi$ & $t_{1 / 2}(\min )$ \\
\hline $1,15^{\circ} \mathrm{C}$ & XAD-4 & 20 & 0.30 & 0.022 & 2.0 & 22.80 & 18.08 & 435 \\
\hline $2,15^{\circ} \mathrm{C}$ & SP-206 & 20 & 0.31 & 0.022 & 4.9 & 9.60 & 14.31 & 147 \\
\hline $3,15^{\circ} \mathrm{C}$ & SP206 & 20 & 0.31 & 0.022 & 1.7 & 27.72 & 15.16 & 448 \\
\hline \multicolumn{9}{|c|}{ Pilot-scale experiments } \\
\hline $4,40^{\circ} \mathrm{C}$ & SP-206 & 0.962 & 0.88 & 0.090 & 170 & 13.26 & 10.18 & 148 \\
\hline $5,15^{\circ} \mathrm{C}$ & SP-206 & 1.060 & 0.88 & 0.090 & 180 & 12.54 & 23.55 & 308 \\
\hline $6,15^{\circ} \mathrm{C}$ & SP-206 & 1.060 & 0.88 & 0.090 & 110 & 20.48 & 28.18 & 598 \\
\hline
\end{tabular}

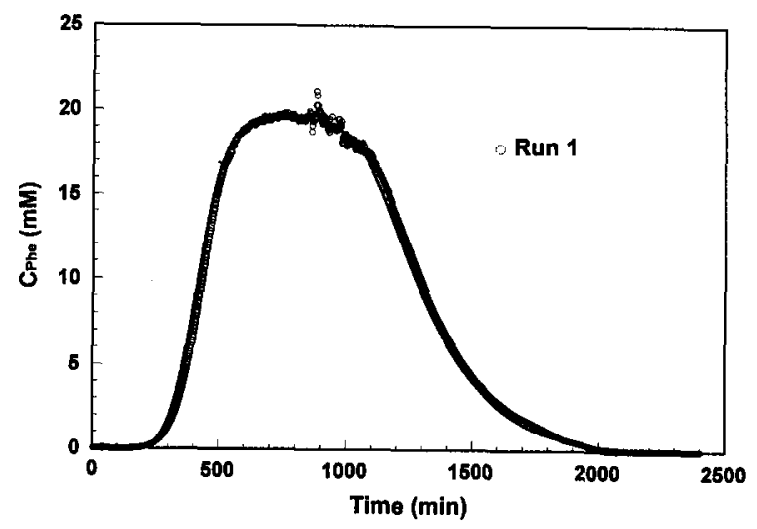

Fig. 6. Experimental and simulated (full lines) concentration histories of fixed-bed adsorption/desorption for phenylalanine on XAD4 at $15^{\circ} \mathrm{C}$.

metric pumping cycles. The experimental conditions are given in Table 4.

Experimental and simulated results are shown in Figs. 6-9. Figs. 6 and 7 illustrate adsorption and desorption curves of phenylalanine on XAD-4 and SP206, respectively. In the adsorption case, in which the outlet concentration results from a step input in concentration, breakthrough curves of a typical $\mathrm{S}$ shape are obtained and this is a conse-

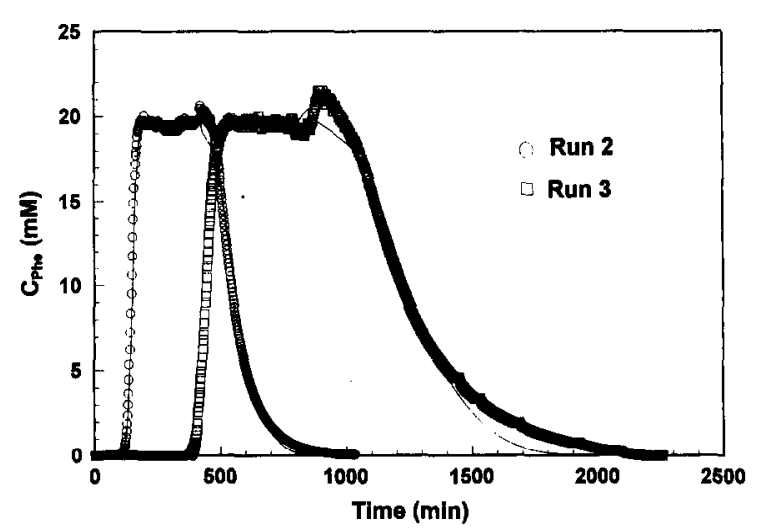

Fig. 7. Experimental and simulated (full lines) concentration histories of fixed-bed adsorption/desorption for phenylalanine on SP206 at $15^{\circ} \mathrm{C}$. Influence of the flowrate: $Q=1.7 \mathrm{ml} \mathrm{min}^{-1}$ for run 3 and $Q=4.9 \mathrm{ml} \mathrm{min}^{-1}$ for run 2 .

quence of the constant pattern resulting from the competition between favorable isotherm and dispersive effects. The observed stoichiometric time $t_{1 / 2}$ is $434 \mathrm{~min}$, in good agreement with the theoretical prediction $t_{1 / 2}[=\tau(1+\xi)]=435 \mathrm{~min}$. Regarding desorption, the outlet concentration results from step decrease in concentration, and now the curve obtained reflects the propagation of a diffusive 


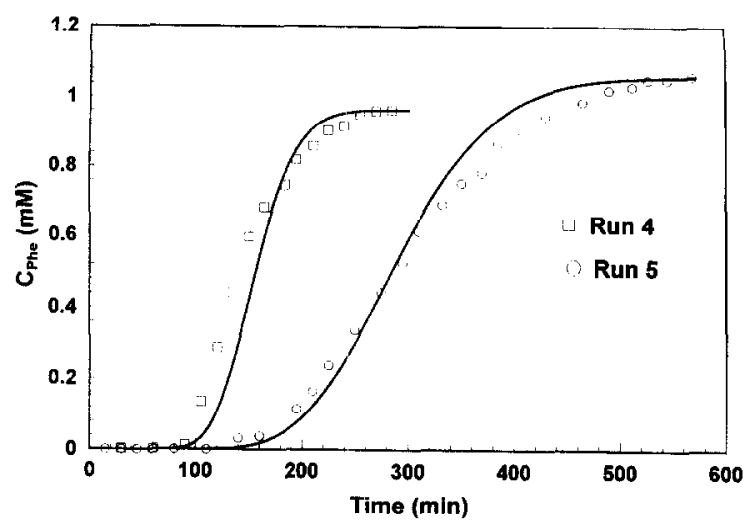

Fig. 8. Experimental and simulated (full lines) concentration historics of breakthrough curves for phenylalaninc on SP206. Influence of the temperature: $T=40^{\circ} \mathrm{C}$ for run 4 and $T=15^{\circ} \mathrm{C}$ for run 5 .

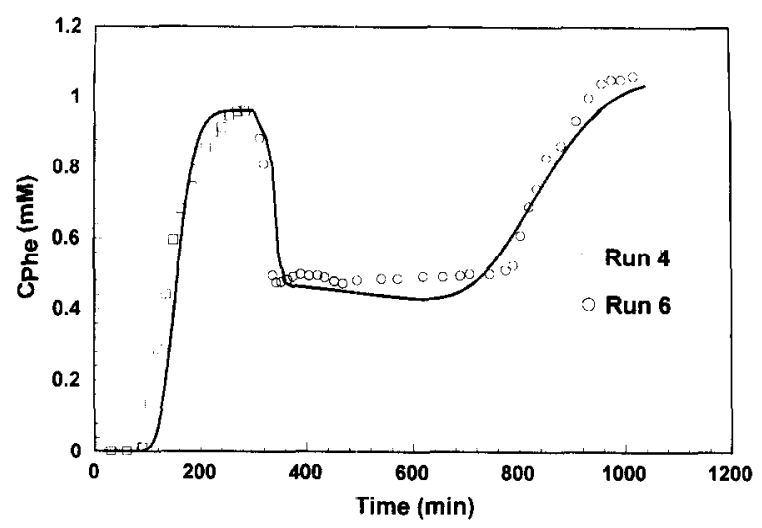

Fig. 9. Experimental and simulated (full lines) concentration histories of temperature swing adsorption for phenylalanine on SP206. Saturation at $40^{\circ} \mathrm{C}$ for run 4 and saturation at $15^{\circ} \mathrm{C}$ for run 6.

wave in which the solute is spread out along the column. This behavior is typical of systems that exhibit favorable equilibrium isotherms.

Fig. 7 shows the effect of the flow-rate $Q$ of the fluid percolated in the column of SP206 adsorbent on the transient adsorption/desorption of phenylalanine. Lower flowrates lead to later breakthrough times. Sharp breakthrough curves are observed. Stoichiometric times are again well predicted. The product $Q t_{1 / 2}$ should be constant if feed concentration was the same; the deviation observed is due to the fact that feed concentrations were slightly different. Furthermore, at these flow- rates the tail of the desorption curve is determined by equilibrium limitations, since the process becomes closer to equilibrium conditions. The model well predicts the experimental results, even though some discrepancy is present during the beginning and the end of the desorption step. The discrepancy is more pronounced for run 3 (Fig. 7) where the experimental concentrations are higher than predicted by the model. In the end of the desorption (tail of the curve), that can probably be attributed to the fact that the isotherm is not correctly represented in the low concentration range.

Fig. 8 shows the effect of the temperature $T$ on the breakthrough curves of phenylalanine in a pliot scale column containing SP206 particles. Increasing the temperature of the solute breakthrough occurs earlier since the amount adsorbed decreases as temperature is increased. This is better seen in the thermal swing adsorption experiment shown by Fig. 9. In this case, the adsorption step at the hot temperature $\left(40^{\circ} \mathrm{C}\right)$ was followed by an adsorption step at the cold temperature $\left(15^{\circ} \mathrm{C}\right)$ with the same feed concentration. Since the adsorbent uptakes less solute at the hot temperature than at the cold temperature, the concentration of solute on the solid increases when the temperature drops. At the same time the fluid concentration decreases and this can be observed in Fig. 9 where it is evident one reduction in the fluid concentration, initially equal to the feed concentration, of about $50 \%$. This is schematically shown in Fig. 10 where $a$ represents the initial state of the bed, $b$ is the final state of the bed and $c$ shows the concentration in the liquid after the passage of the thermal wave. The extra capacity $\Delta q$ is the difference between adsorption capacities at 15 and $40^{\circ} \mathrm{C}$. It should be pointed out that in spite of the temperature change not imposed through the column wall, the rapid decrcasing in the concentration is the result of the fast thermal wave (compared to the wave concentration). According to the equilibrium theory it is possible to calculate the average temperature wave velocity $\left[u_{\mathrm{th}}=u_{\mathrm{i}} /\left(1+\xi_{\mathrm{h}}\right)\right]$ and the average concentration wave velocity $\left[u_{\mathrm{cn}}=u_{\mathrm{i}} /(1+m(T)]\right.$. With $\xi_{\mathrm{h}}=1.2$, $m\left(15^{\circ} \mathrm{C}\right)=24.08, \quad Q=160 \mathrm{ml} \mathrm{min}{ }^{-1}, S=64 \mathrm{~cm}^{2}$ and $\epsilon=0.4$ we obtain $u_{\mathrm{th}}=2.841 \mathrm{~cm} \mathrm{~min}^{-1}$ and 


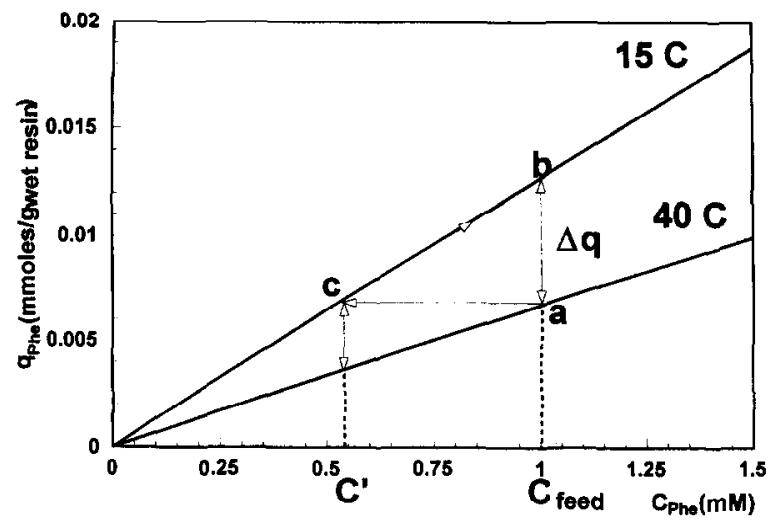

Fig. 10. Scheme illustrating the effect of changing the temperature observed in the temperature swing adsorption experiment (Fig. 9). Prediction with the equilibrium model.

$u_{\mathrm{cn}}=0.249 \mathrm{~cm} \mathrm{~min}^{-1}$. Therefore, the thermal wave requires $31 \mathrm{~min}$ to pass through the bed (which is roughly 2.2 times the space time $\tau$ ) and until that time the wave concentration only penetrates about $9 \%$ of the total length of the fixed bed. Thus, the magnitude of the fluid concentration change in the beginning of the adsorption step at $15^{\circ} \mathrm{C}$ is essentially determined, considering the effect of the temperature shift on the equilibrium isotherm.

For simulation purposes we used an one-dimensional, nonisothermal, heterogeneous model which considers axial dispersion flow, film mass transfer and intraparticle pore diffusion [5,6]. Moreover, the effect of the temperature on the adsorption equilibrium was included in our study as well as heat transfer at the wall. All the model equations were written in dimensionless forms in order to obtain the following parameters:

equilibrium adsorption isotherms parameters

$K_{\mathrm{L}}$ and $Q_{\mathrm{L}}$,

mass Peclet number

$P e=\frac{u L}{\epsilon D_{\mathrm{ax}}}$,

heat Peclet number

$P e_{\mathrm{h}} \frac{G_{\mathrm{f}} C p_{\mathrm{f}} L}{K_{\mathrm{ae}}}$, number of intraparticle mass transfer units

$N_{\mathrm{D}}=\frac{\tau D_{\mathrm{p}}}{R_{0}^{2}}$

number of film mass transfer units

$N_{\mathrm{f}}=\frac{3(1-\epsilon) k_{\mathrm{f}} \tau}{\epsilon R_{0}}$,

number of wall heat transfer units

$N_{\mathrm{hw}}=\frac{h_{\mathrm{we}} a_{\mathrm{w}} \tau}{\rho_{\mathrm{f}} C_{\mathrm{pf}} \epsilon}$

mass capacity factor

$\xi=\frac{(1-\epsilon) q_{\mathrm{E}}^{\prime}}{\epsilon C_{\mathrm{E}}}\left(\right.$ with $\left.q_{\mathrm{E}}^{\prime}=\epsilon_{\mathrm{p}} C_{\mathrm{E}}+\frac{K_{\mathrm{L}} Q_{\mathrm{L}} C_{\mathrm{E}} \rho_{\mathrm{h}}}{1+K_{\mathrm{L}} C_{\mathrm{E}}}\right)$,

thermal capacity parameter

$\xi_{\mathrm{h}}=\frac{(1-\epsilon) \rho_{\mathrm{s}} C_{\mathrm{ps}}}{\epsilon \rho_{\mathrm{f}} C_{\mathrm{pr}}}$.

The values for $K_{\mathrm{L}}$ and $Q_{\mathrm{L}}$ were those reported in the equilibrium study (Table 2 ). To evaluate $N_{\mathrm{f}}$ the film mass transfer coefficient, $k_{\mathrm{f}}$, was estimated from the correlation of Ref. [18]. The adopted values of the thermal coefficients to evaluate $P e_{\mathrm{h}}, N_{\mathrm{hw}}$ and $\xi_{\mathrm{h}}$ have been obtained experimentally in Refs $[5,6]$.

Molecular diffusivities of phenylalanine are estimated by the Wilke-Chang equation [19]. At $15^{\circ} \mathrm{C}, D_{\mathrm{m}}=5.8 \times 10^{-10} \mathrm{~m}^{2} \mathrm{~s}^{-1}$ and at $40^{\circ} \mathrm{C}$, $D_{\mathrm{m}}=1.1 \times 10^{-9} \mathrm{~m}^{2} \mathrm{~s}^{-1}$. The parameters values used in all the simulations are shown in Table 5. These values allowed the best fit of the experimental results by comparing with the results obtained

Table 5

Model parameters for the fixed bed simulations

\begin{tabular}{lrrrrr}
\hline Run & \multicolumn{1}{c}{$N_{\mathrm{D}}$} & \multicolumn{1}{c}{$N_{\mathrm{f}}$} & $N_{\mathrm{hw}}$ & $P e$ & $P e_{\mathrm{h}}$ \\
\hline 1 & 1.42 & 421 & 1.05 & 120 & 80 \\
2 & 3.58 & 816 & 0.44 & 120 & 80 \\
3 & 10.33 & 1679 & 1.28 & 120 & 80 \\
4 & 9.30 & 2192 & 0.30 & 120 & 80 \\
5 & 4.63 & 1335 & 0.28 & 120 & 80 \\
6 & 7.58 & 1913 & 0.46 & 120 & 80 \\
\hline
\end{tabular}


from the numerical solution of the model equations. With the $N_{\mathrm{D}}$ values we find the following effective diffusivities: for the adsorption of phenylalanine on SP-206, $D_{\text {eff }}=8.8 \times 10^{-11} \mathrm{~m}^{2} \mathrm{~s}^{-1}$ at $15^{\circ} \mathrm{C}$ and $D_{\text {eff }}=1.7 \times 10^{-10} \mathrm{~m}^{2} \mathrm{~s}^{-1}$ at $40^{\circ} \mathrm{C}$; for the adsorption of phenylalanine on Amberlite XAD-4, $D_{\text {eff }}=5.30 \times 10^{-11} \mathrm{~m}^{2} \mathrm{~s}^{-1}$ at $15^{\circ} \mathrm{C}$. Since intraparticle porosities are 0.503 for XAD4 and 0.607 for SP206 we obtain tortuosity values of 4.0 for the adsorbent SP206 and 5.5 for the adsorbent XAD-4.

\subsection{Parametric pumping experiment}

The parametric pumping experiment was carried out under the conditions listed in Table 6 . The experimental results are shown in Fig. 11. Top and bottom concentrations of phenylalanine are represented as a function of the time. After $42 \mathrm{~h}(\approx 10$ cycles) the top concentration was increased about $3.6 \times$ feed concentration. Considering that the class of separation desired is the amino acid concentration, this increase is not significant. However, the results demonstrate the capability of thermal parametric pumping of concentrating amino acids from aqueous mixtures.

It is also important to emphasize that the experimental arrangement used, in which the feed is fed on the top reservoir, is more appropriate to purify solvents. Thus, with feed somewhere in the middle of the bed one can expect better results, in terms of the enrichement of the top product.

A comparison between experimental and calculated results can also be seen in Fig. 11. A satisfac-

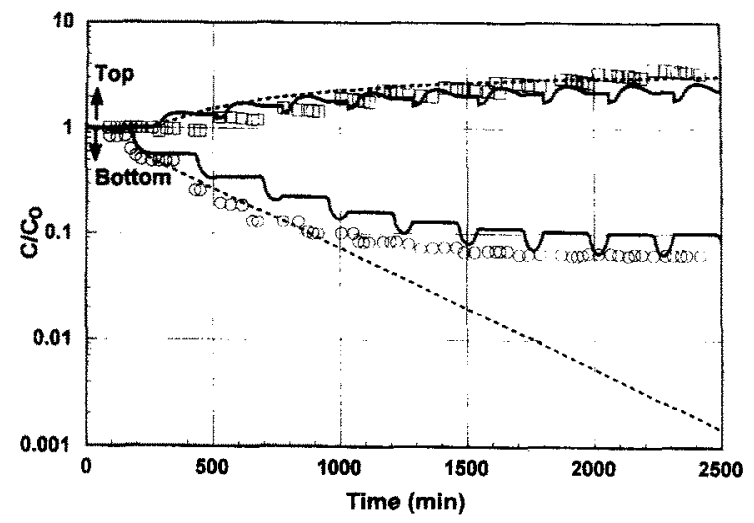

Fig. 11. Top and bottom product concentrations as a function of time in parametric pumping experiment. Full lines are simulated results with the complete model $[P e=120$, $P e_{\mathrm{h}}=80, N_{\mathrm{D}(\mathrm{hc})}=10.54, N_{\mathrm{D}(\mathrm{cc})}=2.08, N_{\mathrm{f}(\mathrm{hc})}=2338, N_{\mathrm{f}(\mathrm{ccc})}=792$, $N_{\text {hw(hc) }}=0.34$ and $\left.N_{\text {hw(cc) }}=0.13\right]$ and dashed lines are simulated results with the equilibrium model $(b=0.35)$.

tory agreement is obtained with the complete model. This model is based on the equations used in the simulations of the adsorption/desorption experiments in fixed bed, and only external balances were included to consider the effects of feed, products and reflux from the reservoirs.

With respect to the equilibrium model, good prediction in the description of the behavior of the top product concentration is observed while the use of this model for the bottom product gives less realistic results, mainly for the final cycles. This was expected since according to this model, the bottom concentration should decrease to zero

Table 6

Experimental conditions of the parametric run

\begin{tabular}{|c|c|c|c|c|}
\hline$L(\mathrm{~m})$ & $d(\mathrm{~m})$ & $\phi_{B}$ & $\phi_{T}$ & $Q(\pi / \omega)\left(\mathrm{m}^{3}\right)$ \\
\hline 0.88 & 0.09 & 0.250 & 0.125 & 0.034 \\
\hline Flowrate in the hot half-cycle $\left(\mathrm{m}^{3} \min ^{-1}\right)$ & $150 \times 10^{-6}$ & & & \\
\hline Flowrate in the cold half-cycle $\left(\mathrm{m}^{3} \min ^{-1}\right)$ & $400 \times 10^{-6}$ & & & \\
\hline Extraction fiowrate from top product $\left(\mathrm{m}^{3} \mathrm{~min}^{-1}\right)$ & $25 \times 10^{-7}$ & & & \\
\hline Extraction flowrate from bottom product $\left(\mathrm{m}^{3} \mathrm{~min}^{-1}\right)$ & $100 \times 10^{-7}$ & & & \\
\hline Feed concentration $\left(\mathrm{mol} \mathrm{m} \mathrm{m}^{-3}\right)$ & 1 & & & \\
\hline Hot half-cycle time (min) & 170 & & & \\
\hline Cold half-cycle time (min) & 85 & & & \\
\hline Hot temperature $\left({ }^{\circ} \mathrm{C}\right)$ & 40 & & & \\
\hline Cold temperature $\left({ }^{\circ} \mathrm{C}\right)$ & 15 & & & \\
\hline Room temperature $\left({ }^{\circ} \mathrm{C}\right)$ & 27 & & & \\
\hline
\end{tabular}


instead of stabilizing around a small value as a result of dispersive kinetic effects. The top concentration predicted by the equilibrium theory at steady-state according to Chen and Hill [20] is $\left\langle C_{\mathrm{TP}}\right\rangle_{\infty}\left(=1+\phi_{\mathrm{B}} / \phi_{\mathrm{T}}\right) \approx 3$.

\section{Conclusions}

Adsorption/desorption of phenylalanine on polymeric adsorbents (XAD4, XAD16, SP206 and SP207) was studied. Batch tests allowed screening of adsorbents on the basis of adsorption capacity. The kinetics of adsorption was studied in laboratory scale with XAD4 and SP206 adsorbents and pilot scale with SP206 columns. Modeling of fixedbed experiments was carried out as the basis of a package for parametric pumping. The package was tested against operation results obtained in pilot parametric pumping unit.

\section{Acknowledgment}

Financial support from Commission of European Communities (contract number ERBCHBGCT930406) is gratefully acknowledged.

\section{Nomenclature}

b separation parameter

$C^{*} \quad$ solute concentration in the fluid phase at equilibrium [mol solute 1 solution $^{-1}$ ]

$d \quad$ column diameter [m]

$D_{\mathrm{m}} \quad$ molecular diffusion coefficient $\left[\mathrm{m}^{2} \mathrm{~s}^{-1}\right]$

$D_{\mathrm{p}} \quad$ intraparticle diffusion coefficient $\left[\mathrm{m}^{2} \mathrm{~s}^{-1}\right]$

$k_{\mathrm{f}} \quad$ film mass transfer coefficient [ $\mathrm{m} \mathrm{s}^{-1}$ ]

$K_{\mathrm{L}} \quad$ parameter of the Langmuir equation [1 solution mol solute ${ }^{-1}$ ]

$K(T)$ slope of the linear isotherm [1 solution $\mathrm{g}$ wet resin $^{-1}$ ]

$L \quad$ bed height [m]

$m(T)$ capacity parameter

$N_{\text {D }} \quad$ number of mass transfer units for pore diffusion

$N_{\mathrm{f}} \quad$ number of film mass transfer units

$N_{\text {hw }} \quad$ number of wall heat transfer units

$\mathrm{Pe} \quad$ mass Peclet number
$P e_{\mathrm{h}} \quad$ thermal Peclet number

$q^{*} \quad$ solute concentration in the adsorbent at equilibrium [mol solute $\mathrm{g}$ wet resin $^{-1}$ ]

$Q \quad$ flowrate of the fluid in the column $\left[\mathrm{m}^{3} \mathrm{~s}^{-1}\right]$

$Q_{\mathrm{L}} \quad$ maximum capacity of the adsorbent [mol solute/g wet resin $^{-1}$ ]

$Q(\pi / \omega)$ reservoir displacement volume $\left[\mathrm{m}^{3}\right]$

$R_{0} \quad$ particle radius [m]

$t_{1 / 2} \quad$ stoichiometric time [min]

$T$ temperature [K]

$u \quad$ superficial velocity $\left[\mathrm{m} \mathrm{s}^{-1}\right]$

\section{Greeks}

$\epsilon$ bed porosity

$\epsilon_{\mathrm{p}}$ intraparticle porosity

$\rho_{\mathrm{h}}$ wet density of the adsorbent $\left[\mathrm{g} \mathrm{m}^{-3}\right]$

$\phi_{\mathrm{B}}$ fraction of the $Q(\pi / \omega)$ that is withdrawn as bottom product

$\phi_{\mathrm{T}}$ fraction of the $Q(\pi / \omega)$ that is withdrawn as top product

$\xi_{\mathrm{h}}$ mass capacity parameter

$\xi_{\mathrm{h}}$ thermal capacity parameter

$\tau$ spatial time in the column [s]

\section{References}

[1] K. Knaebel, For your next separation consider adsorption, Chem. Engng 102 (11) (1995) 92-100.

[2] J. Humphrey, Separation processes: playing a critical role, Chem. Engng Prog. 91 (10) (1995) 31-41.

[3] G. Keller, Adsorption: building upon a solid foundation, Chem. Engng Prog. 91 (10) (1995) 56-67.

[4] R. Wilhelm, A. Rice, A. Bendelius, Parametric pumping: a dynamic method for separating fluid mixtures, Ind. Engng Chem. Fund. 5 (1966) 141-144.

[5] L.M. Ferreira, A.E. Rodrigues, Adsorptive separation by thermal parametric pumping. Part I: modeling and simulation, Adsorption 1 (1995) 220-231.

[6] L.M. Ferreira, A.E. Rodrigues, Adsorptive separation by thermal parametric pumping. Part II: experimental study of the purification of aqueous phenolic solutions at pilot scale, Adsorption 1 (1995) 220-231.

[7] M. Saunders, J. Virow, G. Carta, Uplake of phenylalanine and tyrosine by a strong-acid cation exchanger, AIChE J. 35 (1) (1989) 53-68.

[8] L. Hanak, T. Szanya, G. Simon, Preparative chromatography of aminoacids by ion exchange, 9th International 
Symposium Preparative and Industrial Chromatography, Nancy, 1992 p. 185.

[9] A. Kitakawa, T. Yonemoto, T. Tadaki, A mathematical model for the separation of amino acids using ion cxchange chromatography, Trans. IChemE. 72 (C) (1994) 201-208.

[10] G. Simon, L. Hanak, G. Grevillot, T. Szanya, G. Marton, Preparative scale amino acid separation by thermal parametric pumping on an ion-exchange resin, J. Chromatogr. B. 664 (1995) 17-31.

[11] G. Simon, L. Hanak, G. Grevillot, T. Szanya, G. Marton, Preparative scale separation of amino acids by using thermal ion exchange parametric pumping, Chem. Engng Sci. 52 (1997) 467-480.

[12] A.M. Vasconcellos, A.S. Neto, D.M. Grassiano, C.P. Oliveira, Adsorption chromatography of phenylalanine, Biotechnol. Bioengng 33 (1989) 1324-1329.

[13] C. Ching, D. Ruthven. Sorption and diffusion of some aminoacids in $\mathrm{KX}$ zeolite crystals, Chem. Engng J. 40 (1989) B1-B5.

[14] D.S. Grzegorczyck, Adsorption of aminoacids on porous polymeric adsorbents, M.Sc. thesis, University of Virginia, 1994.

[15] D.S. Grzegorczyck, G. Carta, Adsorption of aminoacids on porous polymeric adsorbents I-equilibrium, Chem. Engng Sci. 51 (5) (1996) 807-817.

[16] D.S. Grzegorczyck, G. Carta, Adsorption of aminoacids on porous polymeric adsorbents I1. Intraparticle mass transport, Chem. Engng Sci. 51 (5) (1996) 819-826.

[17] R. Pigford, B. Baker, D. Blun, An equilibrium theory of the parametric pump, Ind. Engng Chem. Fund. 8 (1969) 144-149.

[18] T. Kataoka, H. Yoshida, K. Ueyama, Mass transfer in laminar region between liquid and packing material surface in the packed bed, J. Chem. Eng. Jpn. 5 (1972) 132.

[19] C.R. Wilke, P. Chang, Correction of diffusion coefficients in dilute solutions, AIChE J. 1 (1955) 264-2701.

[20] H.T. Chen, F.B. Hill, Characteristics of batch, semicontinuous and continuous equilibrium parametric pumps, Sep. Sci. 6 (21) (1971) $411-434$. 